\title{
An investigation into the effectiveness of relative and absolute atmospheric correction for retrieval the TSM concentration in inland waters
}

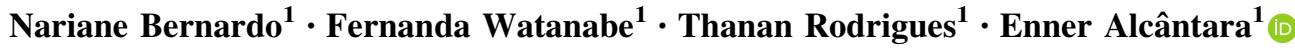

Received: 7 June 2016/Accepted: 13 June 2016/Published online: 21 June 2016

(C) Springer International Publishing Switzerland 2016

\begin{abstract}
The absolute atmospheric correction inputs are not always available, and then such parameters are assumed based on geographical location, acquisition time and sensor type. These assumptions can imply in errors in retrieving the remote-sensing reflectance $\left(R_{r s}\right)$, and affects the optically active compounds estimates. As an alternative, relative atmospheric correction, i.e. radiometric normalization, can be used in cases where there is no information about atmospheric conditions. The main goal of this work was to perform a comparative analysis between absolute and relative atmospheric correction to estimate total suspended matter (TSM) concentrations in the Barra Bonita Hydroelectric Reservoir (São Paulo State, Brazil). The corrections were applied to the operational land imager, on-board Lansat-8 satellite. The $\mathrm{R}_{\mathrm{rs}}$ errors from each correction were computed considering in situ data, and the lowest error was obtained for green spectral band $\left(\mathrm{RMSE}_{\text {absolute }}=11.5 \%\right.$ and $\mathrm{RMSE}_{\text {relative }}=12.3 \%$ ). Using a regional algorithm that was developed using the in situ measurements (the model was $\quad \mathrm{TSM}=1742.7 * \mathrm{~B} 3-5.42, \quad$ with $\quad \mathrm{R}^{2}=0.60$, $\mathrm{p}$-value $=0.05)$, the estimated TSM concentrations from absolute and relative corrections retrieved a RSME of 11 and $6 \%$, respectively. The errors from absolute correction can be originated from the input parameters that were adopted, such as $\mathrm{CO}_{2}$ concentration, initial visibility, and water vapor information. The relative correction can be more appropriate in such cases because, besides atmospheric
\end{abstract}

Enner Alcântara

ennerha@gmail.com

Nariane Bernardo

narianebernardo@gmail.com

1 Department of Cartography, São Paulo State University, Presidente Prudente, SP, Brazil effects, the method try to minimize the illumination variability using normalization between temporal images, which improves the reflectances, and consequently, decreases TSM retrieval errors.

Keywords Inland water - IRMAD - FLAASH - Retrieval errors $\cdot$ Reservoir $\cdot$ Case-2 water

\section{Introduction}

Inland water quality can be assessed using remote sensing data to estimate optically active compounds (AOCs), it means, colored dissolved organic matter (CDOM), total suspended matter (TSM) and phytoplankton (Phy) components. The main advantages of the remote approach are the low-cost, and the spatial and temporal data, which provide synoptic information for retrieving AOCs concentrations. The main challenge in using such orbital data is the atmospheric effects (water vapor absorption and particulate scattering), which in some cases can represent almost $80 \%$ of the radiometric signal registered by satellites (Pahvelan et al. 2014). Regarding on this, to minimize the errors in AOCs estimates owing to atmospheric influences, relative and absolute corrections can be applied to satellite images.

Absolute methods model minimize the absorption and scattering process due to gases and aerosols in atmosphere. Relative methods minimize the atmospheric effects and the surface directionality effects that are resulted from sun angle effects, reducing the noise (residual scatter) and other eventual effects from deterioration in sensor response over the time (Caselles and Garica 1989). Regarding on such effects, these methods can provide a better estimate of remote-sensing reflectance $\left(\mathrm{R}_{\mathrm{rs}}\right)$ from orbital images, and 
consequently result in better TSM estimates? A comparison among relative and absolute atmospheric correction methods to estimate TSM concentration via Landsat- 8 data is the main goal of the present study.

\section{Materials and methods}

\section{Study area}

The Barra Bonita Hydroelectric Reservoir (BBHR), the first of a series of reservoirs in cascade (Fig. 1), was created by damming of Tietê and Piracicaba Rivers, in São Paulo State, Brazil. BBHR has a flooding area of approximately $324.84 \mathrm{~km}^{2}$, presents an average depth about $12.5 \mathrm{~m}$, and its aquatic resources are employed for leisure, fishery, and water supplies (Watanabe et al. 2015;
Alcântara et al. 2016). Studies conducted in the BBHR for more than 50 years have indicated that BBHR presented high levels of nutrients, Chlorophyll- $a$ (Chl- $a$ ), and TSM concentrations (Petesse and Petrere 2007; Smith et al. 2014; Watanabe et al. 2015).

\section{Spectral and limnological data}

Two surveys were conducted in BBHR: one from 5 May 2014 to 8 May 2014, and the second from 13 October 2014 to 17 October 2014, both surveys resulted in 39 sampling locations. The radiance and irradiance measurements were made using the TriOS hyperspectral radiometers (ARCVIS and ACC sensors), considering that radiance sensors have a $7^{\circ}$ field-of-view and irradiance sensor has a cosine collector. The sensors were placed in an azimuth angle of $90^{\circ}$ to minimize the specular reflection (Mobley 1999).

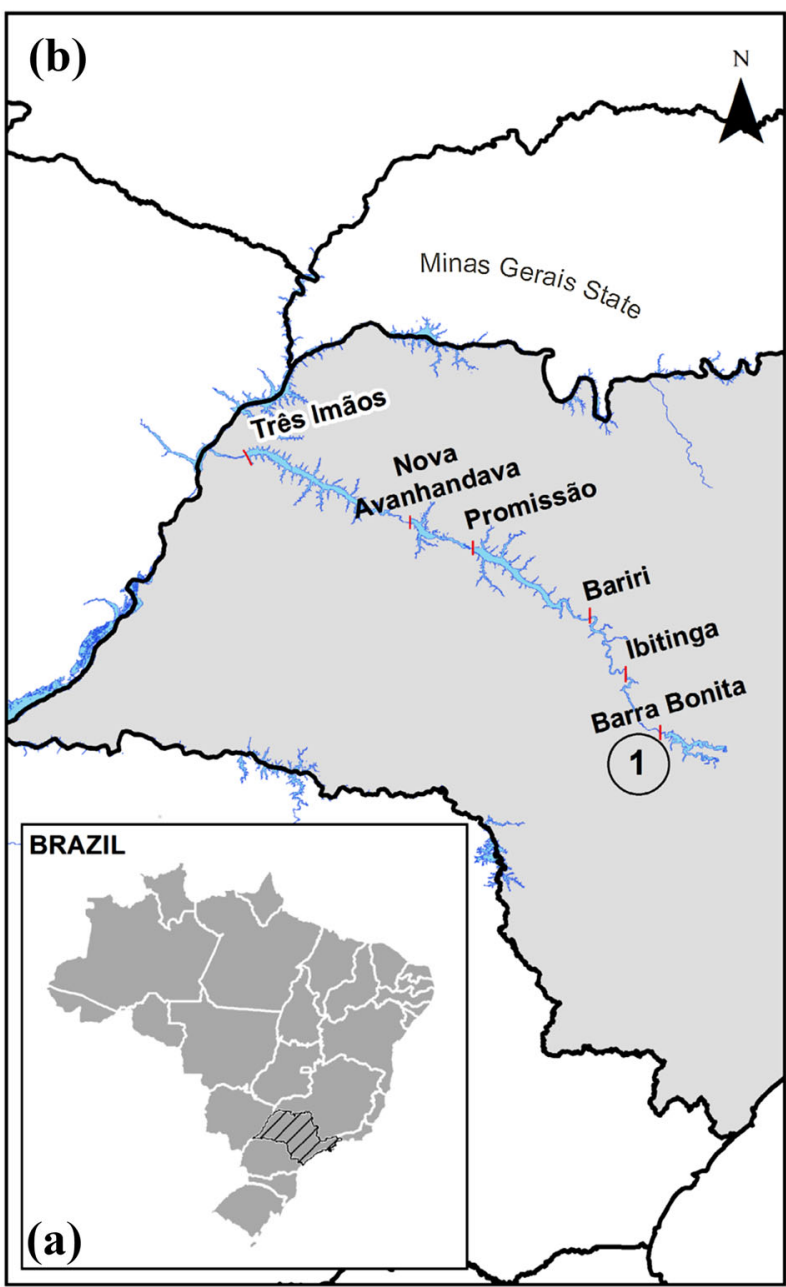

Fig. 1 Study area in Brazil (a), with São Paulo State highlighted; Tietê River and the cascade of reservoirs (b) (from upstream to downstream: Barra Bonita, Ibitinga, Bariri, Promissão, Nova

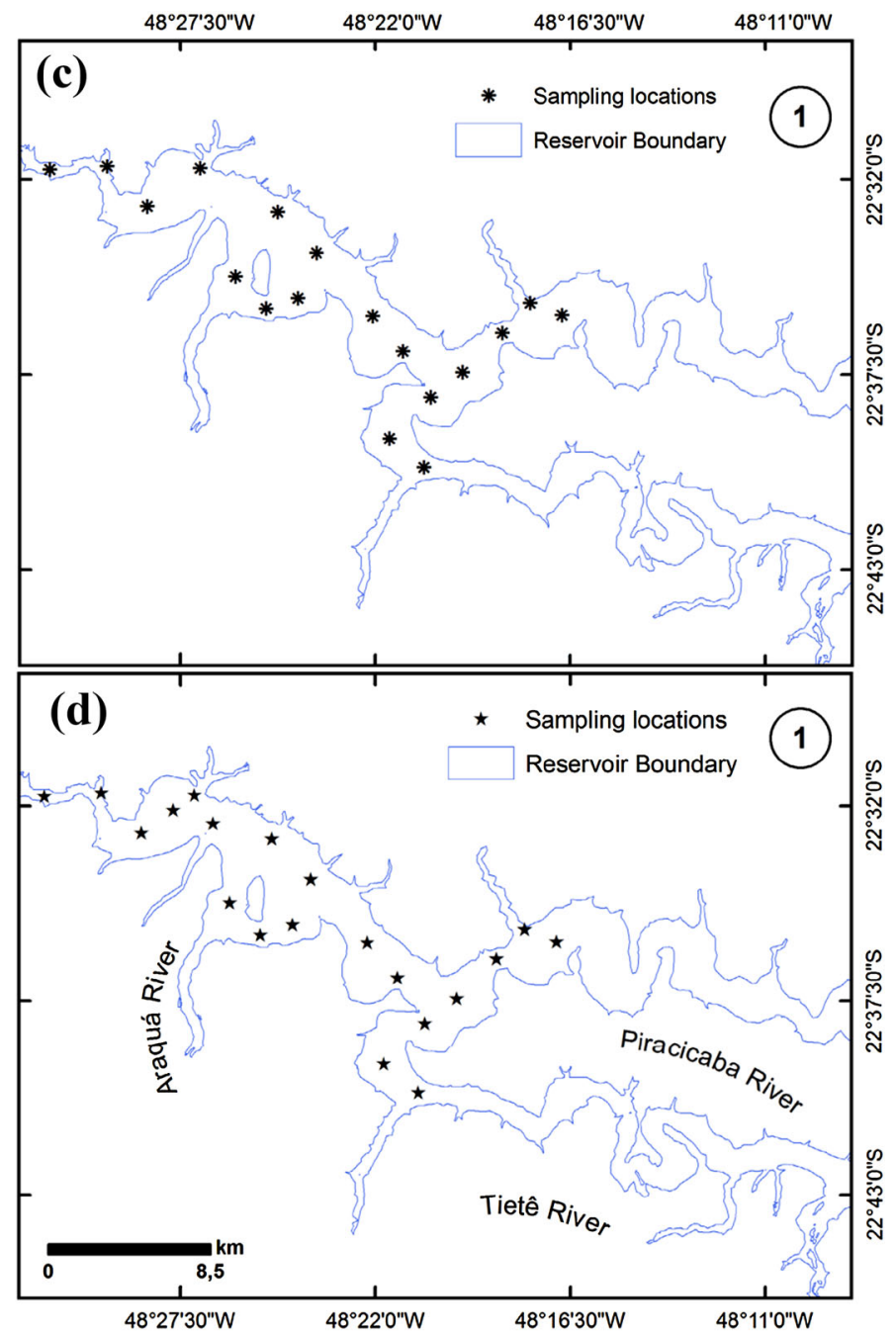

Avanhandava, and Três Irmãos), and number 1 is the BBHR location in the cascading system, with sampling locations from the first (c) and second (d) fieldwork 
The in situ total radiance $\left(\mathrm{L}_{\mathrm{t}}\right.$, units in $\left.\mathrm{W} \mathrm{m} \mathrm{m}^{-2} \mathrm{sr}^{-1}\right)$, the in situ diffuse radiance $\left(\mathrm{L}_{\mathrm{sky}}\right.$, units in $\left.\mathrm{W} \mathrm{m}^{-2} \mathrm{sr}^{-1}\right)$, and the in situ downwelling irradiance $\left(\mathrm{E}_{\mathrm{d}}(0+)\right.$, units in $\left.\mathrm{W} \mathrm{m}^{-2}\right)$ data were used to compute the $\mathrm{R}_{\mathrm{rs}}$ (units in $\mathrm{sr}^{-1}$-Eq. 1).

$R_{\mathrm{rs}}\left(\theta, \phi, \lambda, 0^{+}\right)=\frac{L_{\mathrm{t}}\left(\theta, \phi, \lambda, 0^{+}\right)-0.028 \times L_{\mathrm{sky}}\left(\theta, \phi, \lambda, 0^{+}\right)}{E_{\mathrm{d}}\left(\theta, \phi, \lambda, 0^{+}\right)}$

where: $\theta=$ azimuthal angle (in degrees); $\phi=$ zenithal angle (in degrees); $\lambda=$ wavelength (in nanometres); $0^{+}$. $=$ indicate that measurements were made just above water surface).

The in situ TSM concentrations, established from APHA (1998) protocol for each sampling station, were adopted as reference data for validation (sampling stations were randomly selected) and the TSM retrieval errors were computed from each calibrated model.

\section{TSM models}

Determining of regional models to estimate TSM concentrations were made using the resampled spectral data. The in situ hyperspectral measurements of $\mathrm{R}_{\mathrm{rs}}$ were resampled to the operational land imager (OLI) bands using the outlined Eq. 2, where $R_{\mathrm{rs} \_r}$ (units in $\mathrm{sr}^{-1}$ ) is the resampled (represented by the index " $r$ ") in situ $R_{r s}$; SFR is the Spectral Function Response from each OLI band (Barsi et al. 2014); and min and max are the respective intervals for each OLI spectral band (units in $\mathrm{nm}$ ). This process, socalled band simulation resulted in resampled remote sensing reflectances $\left(\mathrm{R}_{\mathrm{rs} \_\mathrm{r}}\right)$.
$R_{\mathrm{rs} \_\mathrm{r}}=\frac{\int_{\mathrm{x}_{\min }}^{\mathrm{x}_{\max }} R_{\mathrm{rs}} \times \mathrm{SFR} \mathrm{dx}}{\int_{\mathrm{x}_{\min }}^{\mathrm{x}_{\max }} \mathrm{SFR} \mathrm{dx}}$

where: $R_{r s}=$ in situ remote sensing reflectances (in $\mathrm{sr}^{-1}$ ); $S F R=$ Spectral Function Response; $x_{\min }=$ the lower wavelength in OLI channel; $x_{\max }=$ the higher wavelength in OLI channel.

The $R_{\mathrm{rs} \_ \text {r }}$ simulated from 26 sampling locations were used to calibrate the models, and the remainder sampling locations were used to validate the TSM retrieval models (Table 1). The quality of linear, quadratic and exponential adjustments were assessed using $\mathrm{p}$-value and the coefficient of determination $\left(R^{2}\right)$.

\section{Satellite images}

The best regional models were applied to processing OLI image from 13 October, 2014 (the same day that the second survey), identified in Table 2 as OLI1. OLI1 was submitted to two processes: absolute and relative correction. To conduct the relative correction, other image (OLI2), taken on 26 October 2013 was considered as "reference image". Information about both OLI scenes was described in Table 2.

\section{OLI processing}

There are two ways of satellite data processing to minimize the atmospheric effects on radiometric signal, which are the absolute and relative correction. Absolute correction take into account the atmospheric conditions at the same
Table 1 Coefficients of OLI models using resampled data of fieldwork measurements

\begin{tabular}{|c|c|c|c|c|c|c|}
\hline \multirow[t]{2}{*}{ OLI band } & \multirow[t]{2}{*}{$\mathrm{Fit}^{1}$} & \multicolumn{3}{|l|}{ Coefficients } & \multirow[t]{2}{*}{$\mathrm{R}^{2}$} & \multirow[t]{2}{*}{ p-value } \\
\hline & & a & $\mathrm{b}$ & $\mathrm{c}$ & & \\
\hline \multirow[t]{3}{*}{ OLI3 (Green) } & 1 & 1742.7 & -5.61 & - & 0.60 & $<0.001$ \\
\hline & 2 & 2.3 & 141.0 & - & 0.62 & $<0.001$ \\
\hline & 3 & $-84,075.3$ & 3781.0 & -16.8 & 0.66 & $<0.001$ \\
\hline \multirow[t]{3}{*}{ OLI4 (Red) } & 1 & 3416.0 & -8.37 & - & 0.62 & $<0.001$ \\
\hline & 2 & 1.8 & 280.8 & - & 0.64 & $<0.001$ \\
\hline & 3 & $14,325.7$ & 3223.8 & -7.8 & 0.62 & $<0.001$ \\
\hline \multirow[t]{3}{*}{ OLI5 (Infrared) } & 1 & 3952.2 & 2.69 & - & 0.56 & $<0.001$ \\
\hline & 2 & 4.8 & 299.8 & - & 0.48 & $<0.001$ \\
\hline & 3 & 73,580 & 3452.8 & 3.34 & 0.56 & 0.002 \\
\hline
\end{tabular}

1 The adjustments are 1) linear: $\mathrm{y}=\mathrm{ax}+\mathrm{b}$; 2) exponential: $\mathrm{y}=\mathrm{a} \times=\exp (\mathrm{bx})$; 3) quadratic: $\mathrm{y}=\mathrm{ax}^{2}+\mathrm{bx}+\mathrm{c}$; where $\mathrm{a}, \mathrm{b}$ and $\mathrm{c}$ are adjustment coefficients

\begin{tabular}{llll}
\hline Image & Acquisition date & Solar zenith angle & Solar azimuthal angle \\
\hline OLI1 & 13 October 2014 & 29.94 & 63.88 \\
OL2 (reference image) & 26 October 2013 & 26.73 & 71.66 \\
\hline
\end{tabular}

Table 2 Summary of two images used for relative and absolute correction 
time of satellite overpass and aims to acquire absolute reflectances based on the acquisition time of the image. The relative correction, so-called normalization, uses a pair of images (bitemporal images) and aims to match the radiometric data among them using pseudo invariant features (PFIs) (Schroeder et al. 2006). The normalization aims to minimize some atmospheric effects, calibration problems and variations in observation angles and illumination, considering the adjustment of radiometric properties from an image to match with a reference image (Zhang et al. 2010).

The absolute atmospheric correction was accomplished using the fast line-of-sight atmospheric analysis of hypercubes (FLAASH). FLAASH method is based on MODTRAN (MODerate spectral resolution atmospheric TRANsmittance) that includes water vapor content, dioxide carbon concentration, and other atmospheric information for modelling atmospheric effects in the image (Adler-Golden et al. 1999). As output, FLAASH produces a surface reflectance $\left(\mathbf{R}_{\text {sup }}\right)$ image. During FLAASH application the cirrus spectral band was set to calculate water vapor contents and "rural area" was setting to compute the aerosol contributions. The resulted $\mathrm{R}_{\text {sup }}$ image was converted into Rrs image dividing the image by $\pi$ (Moses et al. 2015).

The relative correction was made using the iteratively reweighted multivariate alteration detection (IRMAD). The IRMAD normalization processing is based on to find PFIs in bitemporal images, and using the radiometric information from these targets to make a linear regression that provide a radiometric matching when applied to the entire scene. The normalization considers one scene as reference and the other as the image that should be normalized. The PIFs detection in IRMAD is made using canonical correlation analysis (CCA), which produces MAD variates (from subtracts of two canonical components that occupies the same position) and these variates are ordered by correlation or similarity between the CCA pairs.

Each MAD is reweighted using a measured of no change that are represented by the sum of squared and standardized MAD variate in each iteration. The reweighting process is for increasing the number of PIFs that really did not change over the time. Then, the first MAD indicates the most correlated information between the two scenes, and consequently shows the PIFs, and the last MAD (the number of MAD variates is the same that the spectral bands to compute canonical analysis) shows the less correlated information, which represents the most target variation between the scenes (Canty and Nielsen 2008).

To apply the IRMAD to OLI1 and OLI2 and avoid mismatching among targets, it was necessary to make a geometric correction using nearest neighbor resampling (RMSE $<0.05$ pixel, or $2.5 \mathrm{~m}$ ) and control points welldistributed and well-established within the image. The images were co-registered based on the WGS84 UTM zone $22 \mathrm{~S}$ coordinate system. OLI2 was considered as the reference image because it is the oldest image without cloud coverage, and the OLI1 was used to be normalized considering that it was taken in the same day of the second fieldwork.

The geometric corrected images were used in IRMAD processing. To conduct the normalization process, two steps were made: application of FLAASH to the OLI2; and the IRMAD was conducted using corrected OLI2 and OLI1, which was converted top-of-atmosphere reflectance (RTOA) using calibration scales available in the OLI scene metadata. The FLAASH and IRMAD were conducted using ENVI program and the results retrieved a second image in $R_{\text {sup }}$ that was converted into Rrs dividing by $\pi$. TSM regional models were applied to atmospherically corrected OLI1 and normalized OLI2.

\section{Accuracy assessment methods}

TSM estimates from the OLI images were assessed by calculating the root mean squared error (RMSE-Eq. 3), the mean absolute percent error (MAPE-Eq. 4), and the bias (Eq. 5). The errors analyses were conducted using six sampling locations collected in situ at the same day that OLI overpass.

$$
\begin{aligned}
& \text { RMSE }=\sqrt{\frac{\sum_{i=1}^{n}\left(x_{i}-x_{\text {true }}\right)^{2}}{n}} \times \frac{100 \times n}{\sum_{i=1}^{n} x_{\text {true }}} \\
& \text { MAPE }=\frac{1}{n} \times \sum_{i=1}^{n}\left|\frac{x_{i}-x_{\text {true }}}{x_{\text {true }}}\right| \times 100 \\
& \text { Bias }=\frac{1}{n} \times \sum_{i=1}^{n}\left(x_{i}-x_{\text {true }}\right)
\end{aligned}
$$

where: $x_{\mathrm{i}}=$ estimated TSM concentration; $x_{\text {true }}=$ in situ TSM concentration (reference value) ${ }_{i}=$ first sample used to validate the model; ${ }_{\mathrm{n}}=$ last sample used to validate the model.

\section{Results}

\section{Assessing TSM retrieval algorithms}

TSM retrieval models were calibrated and using the resampled data $\left(\mathrm{R}_{\mathrm{rs} \_}\right)$at the Green, Red, and NIR OLI intervals. The TSM algorithms were assessed using only in situ measurements to compute retrieval errors (Table 3). The RMSE ranged from 22.08 to $30.25 \%$; MAPE ranged from 20.96 to $37.17 \%$, and bias $(\delta)$ from 0.86 to $2.50 \mathrm{mg} \mathrm{L}^{-1}$. 
Table 3 Error analysis of adjusted models using Green, Red and NIR OLI bands

\begin{tabular}{lllll}
\hline OLI band & Fit & RMSE $(\%)$ & MAPE $(\%)$ & $\delta\left(\mathrm{mg} \mathrm{L}^{-1}\right)$ \\
\hline OLI3 (Green) & Linear & 24.02 & 24.09 & 1.90 \\
& Quadratic & 22.08 & 26.19 & 2.50 \\
& Exponential & 28.82 & 37.17 & 1.08 \\
OLI4 (Red) & Linear & 22.62 & 23.34 & 1.18 \\
& Quadratic & 24.94 & 20.96 & 2.34 \\
& Exponential & 22.62 & 22.87 & 1.23 \\
OLI5 (Infrared) & Linear & 23.62 & 24.90 & 0.86 \\
& Quadratic & 30.25 & 35.07 & 1.33 \\
& Exponential & 24.73 & 25.08 & 0.95 \\
\hline
\end{tabular}

RMSE root mean squared error, MAPE mean absolute percent error; $\delta$ bias
Achieved RMSEs from linear and exponential adjustments using OLI3 data are quite similar, as well as the RMSE from linear and quadratic adjustments for OLI4 and OLI5. Given this, a residual analysis was carried out to evaluate if the errors showed equal variances at a $99 \%$ confidence level. The results indicated that all adjustments can be used with no statistical differences. Then, the linear models for each band (OLI3, OLI4, and OLI5) were applied to atmospherically corrected image and to normalized images.

\section{Radiometric signal from OLI images}

Estimated reflectance values from OLI images could be evaluated by comparison among in situ data from each sampling spot (collected at the same day that OLI coverage) and the results from absolute and relative atmospheric corrections (Fig. 2). In general, IRMAD produced a good matching with resampled data that were calculated from fieldwork measurements (adopted as reference data), but there were an overestimating for all values in Blue band $(443 \mathrm{~nm})$. The FLAASH results also produced an overestimation in Blue and NIR bands, but a good matching at the Green band from P3 (Fig. 2c) and P6 (Fig. 2f).

Reflectances from OLI scene were also analysed (Table 4), and showed that the errors from FLAASH correction $(11.5 \%<$ RMSE $<133.45 \%)$ were highest than normalization process that achieved RMSE that ranged from 12.29 to $49.94 \%$. MAPE also shown lower values from IRMAD than FLAASH in all spectral bands.

\section{OLI suitability for TSM estimates}

The linear models for Green, Red and NIR bands were applied to relative and absolute atmospherically corrected images to retrieve a TSM mapping. Each model produced an RMSE of 31.23-101.26\% (Table 5) using the FLAASH output, and 6.44-43.97\% using IR-MAD output. MAPE, as well as RMSE, were bigger from FLAASH than the errors from IR-MAD.

\section{Discussion}

The main problem to apply absolute atmospheric correction considering a time-series is the unavailable information about atmospheric condition at the time of satellite overpass. Furthermore, when the input parameters of atmospheric correction are adopted instead of measured, such assumptions can imply in $\mathrm{R}_{\mathrm{rs}}$. To improve the use of satellite images to estimate OACs concentrations, relative atmospheric correction can be considered an alternative approach. Several studies using relative atmospheric correction were conducted to investigate land cover change detection and agricultural applications (Ell Hajj et al. 2008), but the normalization impacts on TSM estimates were not found in literature. Zhang et al. (2010) used MODIS image and normalization process to estimate TSM concentrations in Taihu Lake, China, but did not evaluate the differences among absolute and relative atmospheric correction. Wu et al. (2015) used OLI image but did not make radiometric normalization for Dongting Lake (China), and the best result produced an RMSE of $55.08 \%$.

Regarding on that, the present study demonstrated that normalized images can reduced a lot the error for TSM retrieval. The best result from FLAASH (absolute correction) was produced by linear model using data of Green band, and retrieved a RMSE of $31.23 \%$. The IRMAD processing (relative correction) produced a RMSE of $6.44 \%$, it means, there was a decrease of $80 \%$ in TSM retrieval errors when the radiometric normalization was conducted. The advantage of normalization processing is the temporal matching with time-series that reduces the atmospheric effects and the geometry/illumination variations, which implied to correct radiometric distortions (Ell Hajj et al. 2008) that absolute correction did not correct. 
(a)

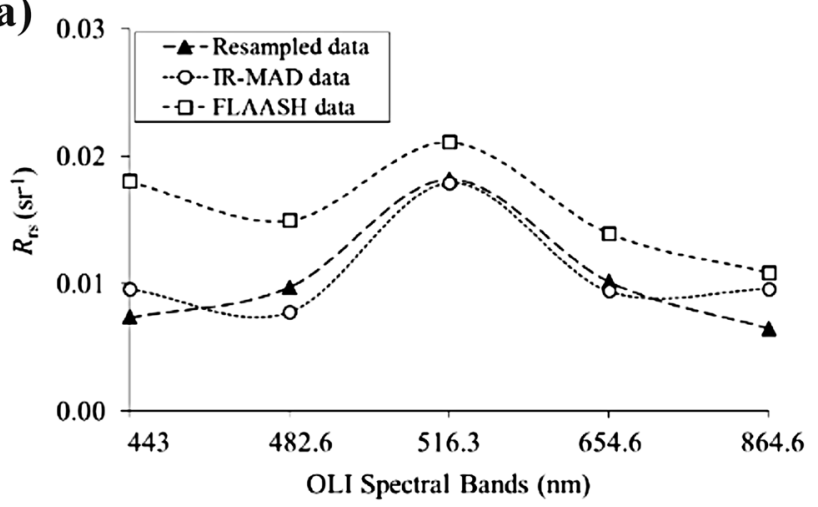

(c)

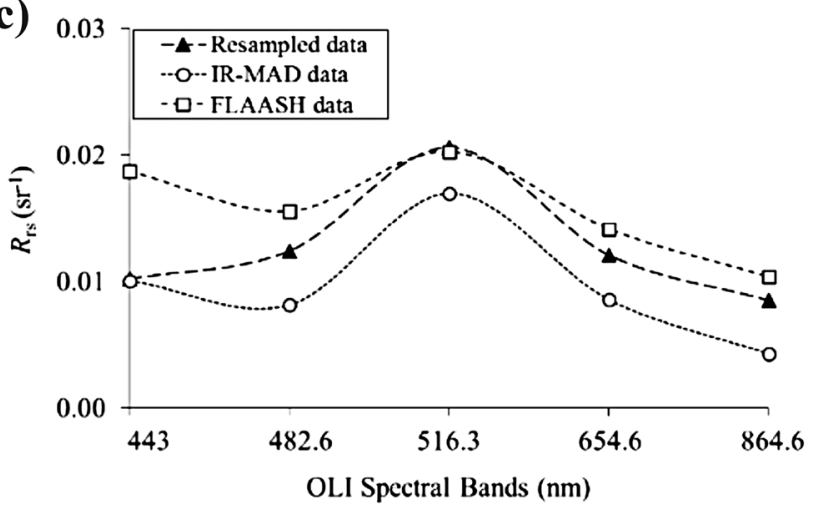

(e)

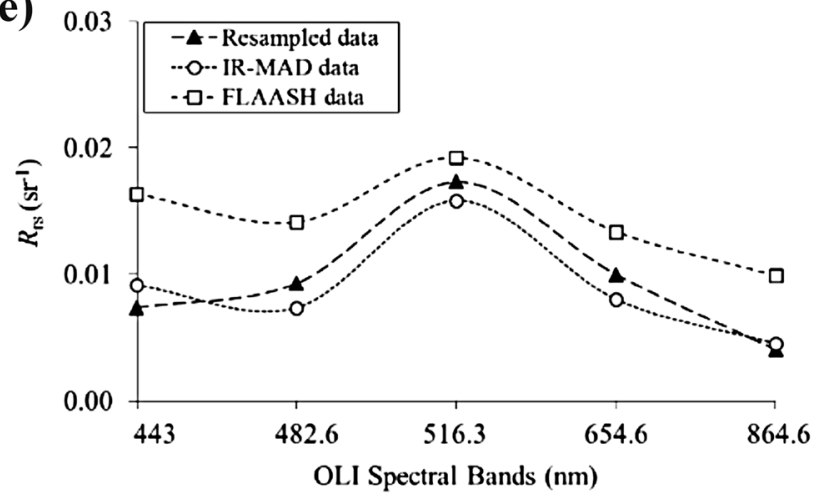

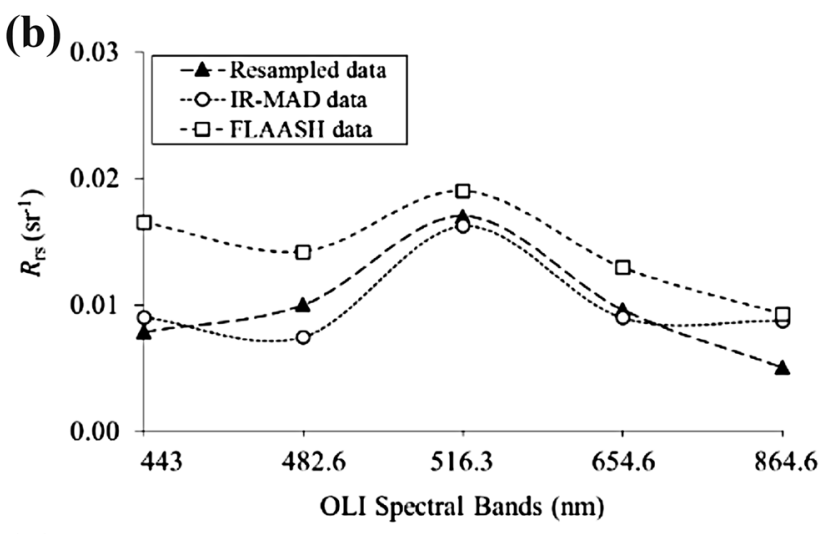

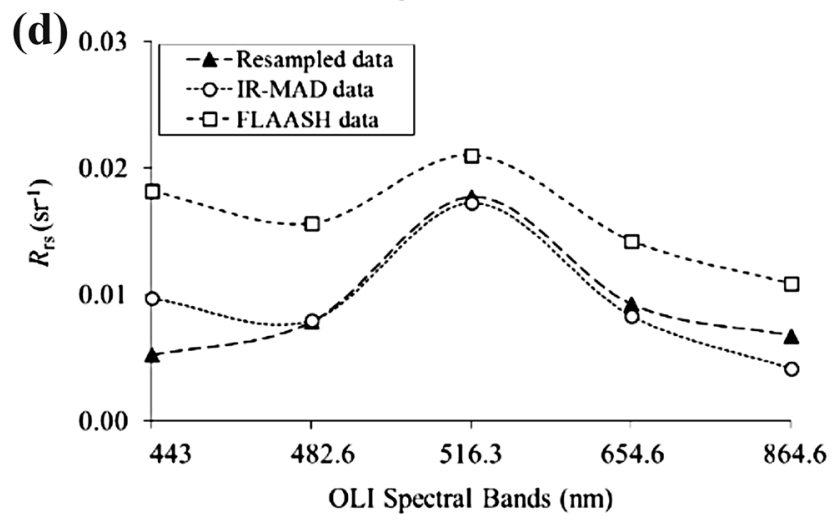

(f)

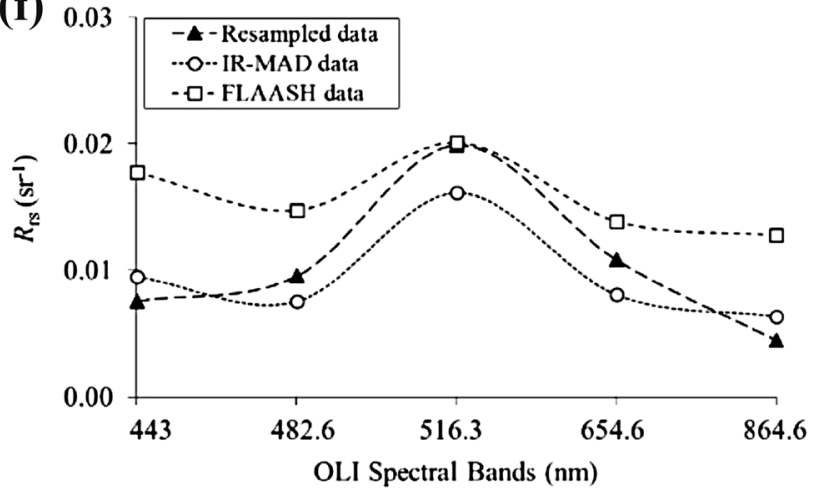

Fig. 2 FLAASH and IRMAD radiometric values for each OLI band at each sampling spot with the following concentrations

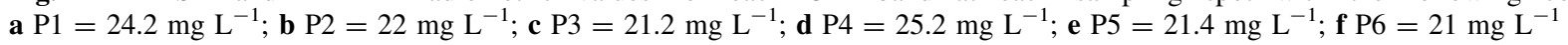

Table 4 Reflectance errors from FLAASH and IRMAD corrections

\begin{tabular}{lccccc}
\hline OLI band & \multicolumn{2}{l}{ RMSE $(\%)$} & & \multicolumn{2}{c}{ MAPE $(\%)$} \\
\cline { 2 - 3 } \cline { 6 - 7 }$\left(\lambda_{\text {central }}\right)$ & FLAASH & IRMAD & & FLAASH & IRMAD \\
\hline Coastal $(440 \mathrm{~nm})$ & 133.45 & 31.22 & & 131.45 & 25.82 \\
Blue $(480 \mathrm{~nm})$ & 53.70 & 25.06 & & 51.73 & 21.84 \\
Green $(560 \mathrm{~nm})$ & 11.50 & 12.29 & & 9.61 & 9.46 \\
Red $(655 \mathrm{~nm})$ & 34.45 & 20.03 & & 33.38 & 16.98 \\
NIR $(865 \mathrm{~nm})$ & 88.29 & 49.97 & & 81.71 & 45.37 \\
\hline
\end{tabular}

It is important to highlight that radiometric distortions are not the only responsible for such differences among IRMAD and FLAASH, the assumptions made from each
Table 5 Error analysis for TSM retrieval using FLAASH and IRMAD outputs

\begin{tabular}{lccccc}
\hline OLI band & \multicolumn{2}{l}{ RMSE $(\%)$} & & \multicolumn{2}{c}{ MAPE $(\%)$} \\
\cline { 2 - 3 } \cline { 6 - 7 }$\left(\lambda_{\text {central }}\right)$ & FLAASH & IRMAD & & FLAASH & IRMAD \\
\hline Green $(560 \mathrm{~nm})$ & 31.23 & 6.44 & & 30.79 & 5.57 \\
Red $(655 \mathrm{~nm})$ & 71.83 & 10.89 & & 71.83 & 7.72 \\
NIR $(865 \mathrm{~nm})$ & 101.16 & 43.97 & & 101.16 & 34.82 \\
\hline
\end{tabular}

method are also a source of errors. The choice of a reference image in a time-series can be a challenge due to the cloud coverage or number of available images, but in this 
paper, the reference image was oldest image (with low calibration problems that rises because of operation time) with no cloud coverage, and coincidentally, the scene was from the same month (October) taken in 2013. Further tests can be made for improve the radiometric process, such as change the reference image or modify the input parameters needed (number of interaction and no-change threshold that was set according to the instructions in ENVI program).

\section{Conclusions}

Absolute atmospheric correction for a time-series is a challenging because the atmospheric effects modify radiometric measurements by a remote sensor. In aquatic systems, the damages of using no atmospherically corrected data can under or overestimate the AOCs concentrations. Atmospheric correction methods aim to minimize the atmospheric effects by separating atmospheric and target signals, but did not correct the surface directionality effects (El Hajj et al. 2008). To improve the estimate reflectances from a remote image, the radiometric normalization procedure can be used, and produces better results than the only atmospheric correction. The normalization process matched the reflectances values between reference image and original image, which consequently provided a better TSM estimates for all OLI spectral bands.

\section{References}

Adler-Golden SM, Matthew MW, Bernstein LS, Levine RY, Berk A, Richtsmeier SC, Acharya PK, Anderson GP, Felde G, Gardner J, Hoke M, Jeong LS, Pukall B, Ratkowski A, Burke HH (1999) Atmospheric correction for shortwave spectral imagery based on MODTRAN4. SPIE Proc Imaging Spectrom 3753:61-69. doi: $10.1117 / 12.366315$

Alcântara E, Watanabe F, Rodrigues T, Bernardo N, Rotta L, Carmo A, Curtarelli M, Imai N (2016) Field measurements of the backscattering coefficient in a cascading reservoir system: first results from Nova Avanhandava and Barra Bonita Reservoirs (São Paulo, Brazil). Remote Sens Lett 7:417-426. doi:10.1080/ 2150704X.2016.1145361

APHA (1998) Standard methods for the examination of water and wastewater. American Public Health Association, Washington
Barsi J, Lee K, Kvaran G, Markham B, Pedelty J (2014) The spectral response of the Landsat- 8 operational land imager. Remote Sens 6(10):10232-10251. doi:10.3390/rs61010232

Canty MJ, Nielsen AA (2008) Automatic radiometric normalization of multitemporal satellite imagery with the iteratively reweighted MAD transformation. Remote Sens Environ 112:1025-1036. doi:10.1016/j.rse.2007.07.013

Caselles V, Garica MJL (1989) An alternative simple approach to estimate atmospheric correction in multitemporal studies. Int $\mathrm{J}$ Remote Sens 10:1127-1134. doi:10.1080/01431168908903951

Ell Hajj M, Bégué A, Lafrance B, Hagolle O, Dedieu G, Rumeau M (2008) Relative radiometric normalization and atmospheric correction of a Spot 5 time series. Sensors 8:2774-2791

ENVI Solutions (2009) ENVI atmospheric correction module: QUAC and FLAASH User's guide. version 4.7. p 44

Mobley CD (1999) Estimation of the remote-sensing reflectance from above-surface measurements. Appl Opt 38(36):7442-7455. doi:10.1364/AO.38007442

Moses WJ, Bowles JH, Corson MR (2015) Expected imporvements in the quantitative remote sensing of optically complex waters with the use of an optically fast hyperspectral spectrometer-a modelling study. Sensors 15:652-6173

NASA (2016) Frequently asked questions about the Landsat Missions. http://landsat.usgs.gov/best_spectral_bands_to_use.php

Pahvelan N, Lee Z, Wei J, Schaaf CB, Schott JR, Berk A (2014) Onorbit radiometric characterization of OLI (Landsat-8) for applications in aquatic remote sensing. Remote Sens Environ 154:272-284. doi:10.1016/j.rse.2014.08.001

Petesse ML, Petrere M, Spigolon RJ (2007) The hydraulic management of the Barra Bonita reservoir (SP, Brazil) as a factor influencing the temporal succession of its fish community. Braz J Biol 67(3):433-445. doi:10.1590/S1519-69842007000300008

Schroeder TA, Cohen WB, Song C, Canty MJ, Yang Z (2006) Radiometric correction of multi-temporal Landsat data for characterization of early successional forest patterns in western Oregon. Remote Sens Environ 3:16-26

Smith WS, Espíndola ELG, Rocha O (2014) Environmental gradient in reservoirs of the medium and low Tietê River: limnological differences through the habitat sequence. Acta Limnol Bras 26(1):73-88. doi:10.1590/S2179-975X2014

TriOS Optical Sensors (2009) Manual: msda_xe 8.5. TriOS, Oldenburg, Germany

Watanabe FSY, Alcântara E, Rodrigues TWP, Imai NN, Barbosa CCF, Rotta LHDS (2015) Estimation of chlorophyll-a concentration and the trophic state of the Barra Bonita Hydroelectric Reservoir using OLI/Landsat-8 images. Int J Environ Health R 12:10391-10417

Wu G, Cui L, Liu L, Chen F (2015) Statistical model development and estimation of suspended particulate concentrations with Landsat 8 OLI in Dongting Lake, China. Int J Remote Sens 36(1):343-360. doi:10.1080/01431161.2014.995273

Zhang Y, Lin S, Liu J, Qian X, Ge Y (2010) Time-series MODIS image-based retrieval and distribution analysis of total suspended matter concentrations in Lake Taihu (China). Int J Environ Health R 3545-3560. doi: 10.3390/ijerph7093545 